\title{
TINGKAT KEPUASAN PASIEN TERHADAP PELAYANAN KESEHATAN DI PUSKESMAS BATURETNO
}

\section{THE LEVEL OF PATIENT SATISFACTION WITH HEALTH SERVICES IN BATURETNO HEALTH CENTERS}

\author{
Sri Handayani \\ Dosen Akper Giri Satria Husada Wonogiri \\ nshanda_77@yahoo.co.id
}

\begin{abstract}
Abstrak
Salah satu upaya pembangunan dalam bidang kesehatan adalah tersedianya pelayanan kesehatan yang berkualitas. Kepuasan pasien merupakan salah satu indikator keberhasilan pemberian pelayanan kesehatan kepada masyarakat. Kepuasan pelayanan jasa kesehatan tercapai jika apa yang didapatkan pasien melebihi harapannya. Rancangan penelitian ini adalah deskriptif kuantitatif yang bertujuan untuk melihat gambaran kepuasan pasien terhadap pelayanan kesehatan, sehingga dapat diketahui unsur yang dipertahankan dan diperbaiki oleh puskesmas dan dapat lebih meningkatkan kualitas pelayanannya. Variabel penelitian adalah kepuasan pasien terhadap pelayanan rawat jalan di puskesmas yang meliputi loket pendaftaran, pelayanan dokter, pelayanan perawat, pelayanan bidan, pelayanan fasilitas medis dan non medis dan keadaan lingkungan fisik dengan subvariabel berwujud, keandalan. empati, ketanggapan, dan jaminan. Populasi penelitian adalah pengunjung Puskesmas Baturetno pada bulan Mei 2016. Metode pengambilan sampel dengan purposive sampling. Sampel diambil 228 orang. Pengumpulan data dimulai dari jam buka pendaftaran sampai selesai dilaksanakan. Instrumen penelitian menggunakan kuesioner yang berisi 30 item. Hasil penelitian dianalisis dengan membandingkan harapan dan pengalaman yang menggambarkan tingkat kepuasan pasien terhadap pelayanan kesehatan dalam aspek berwujud 72,76\%, keandalan 72,09\%, empati 72,89\%, ketanggapan $72,88 \%$, dan jaminan 72,22 \%. Tingkat kepuasan secara keseluruhan, 72,58 \% dikategorikan puas.
\end{abstract}

Kata kunci: Pelayanan kesehatan, Tingkat Kepuasan, Puskesmas

\begin{abstract}
One of the development efforts in the health sector is the availability of quality health care. Patient satisfaction is one indicator of the success of the provision of health services to the community. Satisfaction of health services is achieved if the patients get what exceeded his expectations. The design of this study was quantitative descriptive the aims is to get the picture of patient satisfaction at health care, so it can be known the element that is maintained and improved by the health center and can further improve the quality of service. The research variables were patient satisfaction at outpatient services at the health center that includes the registration booth, physician services, nursing services, midwife services, medical services and non-medical facilities and state of the physical environment with subvariable at tangible, reliability. empathy, responsiveness, and assurance. The population was Baturetno Health Center visitors in May 2016. The sampling method was purposive sampling. The samples was 228 people. The data collected from the opening hours of registration until completed. The research instrument used a questionnaire containing 30 items. The results were analyzed by comparing the expectations and experiences that illustrate the level of patient satisfaction with health services in the in tangible aspects of 72.76\%, $72.09 \%$ reliability, empathy $72.89 \%, 72.88 \%$ responsiveness, and assurance of $72.22 \%$. Overall satisfaction, $72.58 \%$ categorized satisfied.
\end{abstract}

Keywords: Health Services, Satisfaction Level, Health Center 


\section{PENDAHULUAN}

Tersedianya pelayanan kesehatan yang berkualitas bagi masyarakat menjadi hal yang harus mendapat perhatian dari pemerintah sebagai salah satu upaya dalam pembangunan di bidang kesehatan. Pelayanan kesehatan kepada masyarakat bertujuan membentuk masyarakat yang sehat. Puskesmas merupakan kesatuan organisasi fungsional yang menyelenggarakan upaya kesehatan yang bersifat menyeluruh, terpadu, merata dapat diterima dan terjangkau oleh masyarakat dengan peran serta aktif masyarakat dan menggunakan hasil pengembangan ilmu pengetahuan dan teknologi tepat guna, dengan biaya yang dapat dipikul oleh pemerintah dan masyarakat luas guna mencapai derajat kesehatan yang optimal, tanpa mengabaikan mutu pelayanan kepada perorangan (Depkes, 2009). Kedudukan puskesmas sebagai ujung tombak dalam sistem pelayanan kesehatan. Karena puskesmas merupakan lembaga kesehatan yang pertama berhadapan langsung dengan pasien.

Puskesmas memiliki tanggung jawab terhadap wilayah kerja yaitu suatu kecamatan. Puskesmas memiliki visi yaitu tercapainya kecamatan yang sehat. Kecamatan sehat mencakup 4 indikator utama, yaitu hubungan yang sehat, perilaku sehat, cakupan pelayanan kesehatan yang bermutu, dan derajat kesehatan penduduk. Untuk mencapai visi tersebut puskesmas perlu ditunjang dengan pelayanan kesehatan yang bermutu.

Pelayanan kesehatan adalah setiap upaya yang diselenggarakan sendiri atau secara bersama-sama dalam suatu organisasi untuk memelihara dan meningkatkan kesehatan, mencegah dan menyembuhkan penyakit serta memulihkan kesehatan perorangan, keluarga, kelompok dan atupun masyarakat Depkes RI (2009). Kepuasan pasien merupakan indikator utama keberhasilan pemberian pelayanan kesehatan.

Kepuasan pasien adalah suatu tingkat perasaan pasien yang timbul sebagai akibat dari kinerja layanan kesehatan yang diperoleh setelah pasien membandingkan dengan apa yang dirasakan. Pasien akan merasa puas apabila kinerja layanan kesehatan yang diperoleh sama atau melebihi harapan (Pohan, 2006). Ada 5 (lima) dimensi yang mewakili persepsi konsumen terhadap suatu kualitas pelayanan jasa, yaitu: keandalan, ketanggapan, jaminan, empati dan berwujud
Keandalan (reliability) adalah dimensi yang mengukur keandalan suatu pelayanan jasa kepada konsumen. Keandalan didefinisikan sebagai kemampuan untuk memberikan pelayanan sesuai dengan yang dijanjikan secara akurat dan terpercaya.

Ketanggapan (responsiveness) adalah kemampuan untuk membantu konsumen dan memberikan pelayanan dengan cepat kepada konsumen. Dimensi ketanggapan merupakan dimensi yang bersifat paling dinamis. Hal ini dipengaruhi oleh faktor perkembangan teknologi. Salah satu contoh aspek ketanggapan dalam pelayanan adalah kecepatan.

Jaminan (assurance) adalah dimensi kualitas pelayanan yang berhubungan dengan kemampuan dalam menanamkan kepercayaan dan keyakinan kepada konsumen. Dimensi jaminan meliputi kemampuan tenaga kerja atas pengetahuan terhadap produk meliputi kemampuan karyawan dan kesopanan dalam memberi pelayanan, ketrampilan dalam memberikan keamanan di dalam memanfaatkan jasa yang ditawarkan dan kemampuan di dalam menanamkan kepercayaan konsumen terhadap jasa yang ditawarkan.

Empati (emphaty) adalah kesediaan untuk peduli dan memberikan perhatian yang tulus dan bersifat pribadi kepada konsumen (pengguna jasa). Dimensi empati adalah dimensi yang memberikan peluang besar untuk menciptakan pelayanan yang "surprise" yaitu sesuatu yang tidak diharapkanpengguna jasa tetapi ternyata diberikan oleh penyedia jasa.

Berwujud (tangible) didefinisikan sebagai penampilan fasilitas peralatan dan petugas yang memberikan pelayanan jasa karena suatu service jasa tidak dapat dilihat, dicium, diraba atau didengar maka aspek berwujud menjadi sangat penting sebagai ukuran terhadap pelayanan jasa. Untuk mengetahui tingkat keberhasilan pemberian pelayanan kesehatan khususnya di puskesmas perlu melakukan pengukuran tingkat kepuasan pasien (pelanggan).

Puskesmas Baturetno terletak di Jl. Baturetno - Pacitan km. 1, Kecamatan Baturetno Kabupaten Wonogiri. Wilayah kerja Puskesmas Baturetno terdiri dari sembilan desa antara lain Desa Baturetno, Desa Talunombo, Desa Saradan, Desa Temon, Desa Belikurip, Desa Watuagung, Desa Balepanjang, Desa Glesungrejo, dan Desa Gambiranom. Kegiatan pokok yang dilakukan di puskesmas meliputi: Kesehatan ibu dan anak (KIA), Keluarga Berencana (KB), Usaha 
peningkatan gizi, Kesehatan lingkungan, Pencegahan dan pemberantasan penyakit menular, Pengobatan termasuk pelayanan darurat karena kecelakaan, Penyuluhan kesehatan masyarakat, Usaha kesehatan sekolah, Perawatan kesehatan masyarakat, Kesehatan gigi dan mulut, Kesehatan jiwa, Kesehatan mata, Laboratorium sederhana, Pencatatan dan pelaporan dalam rangka sistem informasi kesehatan, Posyandu, Posyandu lanjut usia, Pembinaan pengobatan tradisional dan sistem rujukan. Saat ini Puskesmas Baturetno sedang mempersiapkan diri untuk melakukan akreditasi sehingga memerlukan beberapa masukan salah satunya dari pelanggan yaitu pasien sebagai bahan acuan untuk memberikan pelayanan kesehatan yang sesuai dengan standar.

Berdasarkan latar belakang masalah di atas penulis tertarik untuk melakukan penelitian tentang Tingkat Kepuasan Pasien Tentang Pelayanan Kesehatan di Puskesmas Baturetno dengan tujuan untuk melihat gambaran kepuasan pasien terhadap pelayanan kesehatan, sehingga dapat diketahui unsur yang dipertahankan dan diperbaiki oleh puskesmas dan dapat lebih meningkatkan kualitas pelayanannya.

\section{METODE PENELITIAN}

Rancangan penelitian ini adalah deskriptif kuantitatif dengan menggunakan variabel kepuasan dan subvariabel keandalan, ketanggapan, jaminan, empati dan berwujud. Populasi penelitian adalah pengunjung Puskesmas Baturetno pada bulan Mei 2016. Metode pengambilan sampel dengan purposive sampling. Sampel diambil 228 orang. Pengumpulan data dimulai dari jam buka pendaftaran sampai selesai dilaksanakan. Instrumen penelitian menggunakan kuesioner yang berisi 30 item pernyataan tentang kenyataan yang diterima dan harapan terhadap pelayanan kesehatan di puskesmas yang meliputi pelayanan loket pendaftaran, pelayanan dokter, pelayanan perawat, pelayanan bidan pelayanan fasilitas medis/non medis dan keadaan lingkungan fisik dan seberapa penting pernyataan itu bagi pasien yang terdiri dari subvariabel berwujud sebanyak 6 pernyataan, subvariabel empati sebanyak 6 pernyataan, subvariabel ketanggapan sebanyak 6 pernyataan, subvariabel jaminan sebanyak 6 item pernyataan dan subvariabel keandalan sebanyak 6 pernyataan. Responden diminta untuk memberikan tanda (x) pada pernyataan yang sesuai dengan kenyataan dan harapan. Untuk pernyataan yang sesuai dengan kenyataan yang diterima, skor 1 apabila pasien sangat tidak puas, skor 2 apabila pasien tidak puas, skor 3 apabila pasien cukup puas, skor 4 apabila pasien puas dan skor 5 apabila pasien sangat puas. Untuk harapan pasien terhadap pelayanan kesehatan puskesmas, skor 1 apabila pernyataan sangat tidak penting, skor 2 apabila pernyataan tidak penting, skor 3 apabila pernyataan cukup penting, skor 4 apabila pernyataan penting dan skor 5 apabila pernyataan sangat penting. Tehnik analisa data menggunakan skala Likert dan pengolahannya menggunakan skor

\section{HASIL PENELITIAN DAN PEMBAHASAN}

Tabel 1. Distribusi Responden Berdasarkan Jenis Kelamin

\begin{tabular}{|c|c|c|c|}
\hline No & Jenis Kelamin & Frekwensi & $\%$ \\
\hline 1 & Laki - laki & 110 & 48,25 \\
\hline 2 & Perempuan & 118 & 51,75 \\
\hline & & 228 & 100 \\
\hline
\end{tabular}

Sumber: Data primer

Berdasarkan tabel 1 diatas diperoleh data distribusi responden berdasarkan jenis kelamin hampir seimbang antara responden yang berjenis kelamin laki - laki dan perempuan, dimana responden yang berjenis kelamin laki - laki sebanyak 48,25 \% sedangan responden yang berjenis kelamin perempuan sebanyak $51,75 \%$.

Tabel 2. Distribusi Responden Berdasarkan Umur

\begin{tabular}{|c|c|c|c|}
\hline No & Umur & Frekwensi & $\%$ \\
\hline 1 & $17-24$ tahun & 42 & 18,42 \\
\hline 2 & $25-34$ tahun & 88 & 38,60 \\
\hline 3 & $35-49$ tahun & 56 & 24,56 \\
\hline 4 & $50-64$ tahun & 33 & 14,47 \\
\hline 5 & $>65$ tahun & 9 & 3,95 \\
\hline \multicolumn{2}{|r|}{ TOTAL } & 228 & 100 \\
\hline
\end{tabular}

Sumber: Data primer

Dari tabel 2 di atas distribusi responden berdasarkan umur diperoleh data bahwa jumlah responden tertinggi berusia $25-34$ tahun yaitu sebesar 38,60\% dan responden terendah berusia lebih dari 65 tahun yaitu sebesar 3,95\%. 
Tabel 3. Distribusi Responden Berdasarkan Tingkat Pendidikan

\begin{tabular}{|c|c|c|c|}
\hline No & $\begin{array}{c}\text { Tingkat } \\
\text { Pendidikan }\end{array}$ & Frekwensi & $\%$ \\
\hline 1 & SD & 22 & 9,65 \\
\hline 2 & SMP & 52 & 22,80 \\
\hline 3 & SMA & 96 & 42,11 \\
\hline 4 & Diploma & 39 & 17,11 \\
\hline 5 & Sarjana & 19 & 8,33 \\
\hline \multicolumn{2}{|l|}{ TOTAL } & & 100 \\
\hline
\end{tabular}

Sumber: Data primer

Dari tabel 3. Di atas diperoleh data berdasar tingkat pendidikan sebanyak $42,11 \%$ pendidikan responden adalah Sekolah Menengah Atas (SMA)
Tabel 4. Distribusi Responden Berdasarkan Pekerjaan

\begin{tabular}{|c|l|c|c|}
\hline No & \multicolumn{1}{|c|}{ Pekerjaan } & Frekwensi & $\%$ \\
\hline 1 & Pegawai Negeri & 37 & 16,23 \\
\hline 2 & Pegawai Swasta & 42 & 18,42 \\
\hline 3 & Petani & 58 & 25,44 \\
\hline 4 & Pedagang & 32 & 14,03 \\
\hline 5 & Buruh & 24 & 10,53 \\
\hline 6 & Tidak Bekerja & 13 & 5,70 \\
\hline 7 & Lain - lain & 22 & 9,65 \\
\hline & & 228 & 100 \\
\hline
\end{tabular}

Sumber: Data primer

Dari tabel 4. Diperoleh data sebagian besar responden adalah bekerja sebagai petani yaitu sebesar $25,44 \%$.

Tabel 5. Daftar Pernyataan Kepuasan Responden Terhadap Pelayanan

Rawat Jalan Di Puskesmas Baturetno

\begin{tabular}{|c|c|}
\hline Variabel & Pertanyaan \\
\hline $\begin{array}{l}\text { Pelayanan } \\
\text { Loket } \\
\text { Pendaftaran }\end{array}$ & $\begin{array}{l}\text { 1. P.1 Jam buka pendaftaran sesuai jadwal } \\
\text { 2. P.2 Pendaftaran pasien berurutan dari yang datang lebih awal } \\
\text { 3. P.3 Prosedur pendaftaran mudah dan tdk berbelit - belit } \\
\text { 4. P.4 Petugas memberikan pelayanan dengan sopan } \\
\text { 5. P.5 Waktu tunggu sebelum periksa tdk terlalu lama }\end{array}$ \\
\hline $\begin{array}{l}\text { Pelayanan } \\
\text { Dokter }\end{array}$ & $\begin{array}{l}\text { 6. P.6 Dokter jaga selalu ada di puskesmas } \\
\text { 7. P.7 Dokter memberikan informasi yang jelas dan mudah dimengerti tentang penyakit yang } \\
\text { diderita } \\
\text { 8. P.8 Dokter memeriksa dengan ramah dan sopan } \\
\text { 9. P.9 Dokter memberikan tindakan yang cepat pada saat dibutuhkan } \\
\text { 10. P.10 Dokter memeriksa pasien tanpa memandang status pasien }\end{array}$ \\
\hline $\begin{array}{l}\text { Pelayanan } \\
\text { Perawat }\end{array}$ & $\begin{array}{l}\text { 11. P.11 Perawat memberikan pelayanan dengan ramah dan sopan } \\
\text { 12. P.12 Perawat memberikan perhatian terhadap keluhan penyakit yang diderita } \\
\text { 13. P.13 Perawat melayani anda dengan tulus dan penuh kasih sayang } \\
\text { 14. P.14 Perawat berkomunikasi dengan santai dan Terbuka } \\
\text { 15. P.15 Perawat memberikan penjelasan yang mudah dimengerti tentang keperawatan yang } \\
\text { diderita }\end{array}$ \\
\hline $\begin{array}{l}\text { Pelayanan } \\
\text { Bidan }\end{array}$ & $\begin{array}{l}\text { 16. P.16 Bidan bekerja selama } 24 \text { jam } \\
\text { 17.P.17 Bidan memberikan motivasi dan perhatian terhadap pasien } \\
\text { 18. P.18 Bidan mendengarkan keluhan yang disampaikan pasien } \\
\text { 19. P.19 Bidan melayani anda dengan tulus dan penuh kasih sayang } \\
\text { 20. P.20 Bidan memberikan penjelasan yang mudah dimengerti tentang keperawatan yang diderita }\end{array}$ \\
\hline $\begin{array}{l}\text { Pelayanan } \\
\text { Fasilitas } \\
\text { Medis dan } \\
\text { Non Medis }\end{array}$ & $\begin{array}{l}\text { 21. P.21 Waktu tunggu untuk melayani } \\
\text { 22.P.22 Ketersediaan obat-obatan memadai } \\
\text { 23. P.23 Kemampuan berkomunikasi petugas apotek baik } \\
\text { 24. P.24 Petugas apotek memberikan penjelasan yang mudah dimengerti tentang penggunaan obat } \\
\text { 25.P.25 Pelayanan petugas apotek sopan dan ramah }\end{array}$ \\
\hline $\begin{array}{l}\text { Keadaan } \\
\text { Lingkungan } \\
\text { Fisik }\end{array}$ & $\begin{array}{l}\text { 26. P.26 Ruang tunggu nyaman } \\
\text { 27. P.27 Ruang pemeriksaan bersih } \\
\text { 28. P.28 Ventilasi udara cukup } \\
\text { 29. P.29 Kamar mandi /WC bersih } \\
\text { 30.P.30 Penerangan yang ada cukup }\end{array}$ \\
\hline
\end{tabular}


PROFESI, Volume 14, Nomor 1, September 2016

Tabel 6. Distribusi Harapan dan Pelaksanaan Responden Terhadap Pelayanan Rawat Jalan di Puskesmas Baturetno

\begin{tabular}{|c|c|c|c|c|c|c|c|c|c|c|c|c|c|}
\hline \multirow{2}{*}{$\begin{array}{c}\text { Pernya } \\
\text { taan }\end{array}$} & \multicolumn{5}{|c|}{ Harapan } & \multirow[t]{2}{*}{ Jumlah } & \multicolumn{5}{|c|}{ Pelaksanaan } & \multirow[t]{2}{*}{ Bobot } & \multirow{2}{*}{$\begin{array}{c}\text { Nil. } \\
\text { Indek } \\
\text { Kinerja } \\
\end{array}$} \\
\hline & STPt & $\mathrm{TPt}$ & $\mathrm{CPt}$ & $\mathrm{Pt}$ & SPt & & STPs & TPs & CPs & Ps & SPs & & \\
\hline \multicolumn{14}{|c|}{ Pelayanan Loket Pendaftaran } \\
\hline P.1 & 3 & 17 & 77 & 115 & 16 & 228 & 3 & 34 & 231 & 460 & 80 & 808 & 70,87 \\
\hline P.2 & 5 & 15 & 75 & 116 & 17 & 228 & 5 & 30 & 225 & 464 & 85 & 809 & 70,96 \\
\hline P.3 & 12 & 10 & 60 & 120 & 26 & 228 & 12 & 20 & 180 & 480 & 130 & 822 & 72,10 \\
\hline P.4 & 9 & 19 & 73 & 100 & 27 & 228 & 9 & 38 & 219 & 400 & 135 & 801 & 70,26 \\
\hline P.5 & 7 & 21 & 76 & 112 & 12 & 228 & 7 & 42 & 228 & 448 & 60 & 785 & 68,86 \\
\hline \multicolumn{14}{|c|}{ Pelayanan Dokter } \\
\hline P.6 & 5 & 15 & 88 & 113 & 7 & 228 & 5 & 30 & 264 & 452 & 35 & 786 & 68,95 \\
\hline P.7 & 9 & 19 & 60 & 130 & 10 & 228 & 9 & 38 & 180 & 520 & 50 & 797 & 69,91 \\
\hline P.8 & 7 & 20 & 73 & 122 & 6 & 228 & 7 & 40 & 219 & 488 & 30 & 784 & 68,77 \\
\hline P.9 & 4 & 11 & 75 & 125 & 13 & 228 & 4 & 22 & 225 & 500 & 65 & 816 & 71,58 \\
\hline P.10 & 6 & 18 & 67 & 123 & 14 & 228 & 7 & 42 & 228 & 448 & 60 & 785 & 68,86 \\
\hline \multicolumn{14}{|c|}{ Pelayanan Perawat } \\
\hline P.11 & 3 & 3 & 86 & 124 & 12 & 228 & 3 & 6 & 258 & 496 & 60 & 823 & 72,19 \\
\hline P.12 & 8 & 9 & 79 & 122 & 10 & 228 & 8 & 18 & 237 & 488 & 50 & 801 & 70,26 \\
\hline P.13 & 0 & 5 & 68 & 135 & 20 & 228 & 0 & 10 & 204 & 540 & 100 & 854 & 74,91 \\
\hline P.14 & 0 & 9 & 77 & 126 & 19 & 228 & 0 & 18 & 231 & 504 & 95 & 848 & 74,39 \\
\hline P.15 & 2 & 7 & 82 & 128 & 9 & 228 & 2 & 14 & 246 & 512 & 45 & 819 & 71,84 \\
\hline \multicolumn{14}{|c|}{ Pelayanan Bidan } \\
\hline P.16 & 4 & 5 & 57 & 130 & 32 & 228 & 4 & 10 & 171 & 520 & 160 & 865 & 75,88 \\
\hline P.17 & 0 & 2 & 87 & 127 & 12 & 228 & 0 & 4 & 261 & 508 & 60 & 833 & 73,07 \\
\hline P.18 & 7 & 8 & 46 & 133 & 34 & 228 & 7 & 16 & 138 & 532 & 170 & 863 & 75,70 \\
\hline P.19 & 6 & 3 & 64 & 132 & 23 & 228 & 6 & 6 & 192 & 528 & 115 & 847 & 74,30 \\
\hline P.20 & 0 & 9 & 66 & 128 & 25 & 228 & 0 & 18 & 198 & 512 & 125 & 853 & 74,82 \\
\hline \multicolumn{14}{|c|}{ Pelayanan Fasilitas Medis dan non Medis } \\
\hline P.21 & 2 & 7 & 66 & 131 & 22 & 228 & 2 & 14 & 198 & 524 & 110 & 848 & 74,39 \\
\hline P.22 & 7 & 4 & 57 & 130 & 30 & 228 & 7 & 8 & 171 & 520 & 150 & 856 & 75,09 \\
\hline P.23 & 9 & 9 & 68 & 129 & 13 & 228 & 9 & 18 & 204 & 516 & 65 & 812 & 71,23 \\
\hline P.24 & 3 & 6 & 74 & 137 & 8 & 228 & 3 & 12 & 222 & 548 & 40 & 825 & 72,37 \\
\hline P. 25 & 2 & 5 & 68 & 125 & 28 & 228 & 2 & 10 & 204 & 500 & 140 & 856 & 75,09 \\
\hline \multicolumn{14}{|c|}{ Keadaan Lingkungan Fisik } \\
\hline P.26 & 1 & 9 & 68 & 126 & 24 & 228 & 1 & 18 & 204 & 504 & 120 & 847 & 74,30 \\
\hline P.27 & 5 & 7 & 70 & 129 & 18 & 228 & 5 & 14 & 210 & 516 & 90 & 835 & 73,25 \\
\hline P.28 & 0 & 7 & 69 & 130 & 22 & 228 & 0 & 14 & 207 & 520 & 110 & 851 & 74,65 \\
\hline P.29 & 7 & 3 & 65 & 125 & 28 & 228 & 7 & 6 & 195 & 500 & 140 & 848 & 74,39 \\
\hline P.30 & 3 & 5 & 67 & 132 & 20 & 228 & 3 & 10 & 201 & 528 & 100 & 842 & 73,86 \\
\hline
\end{tabular}

Sumber: Data primer 
Pelayanan Loket Pendaftaran

Dari tabel 6 diatas, pada kinerja terhadap variabel pelayanan loket pendaftaran, pada kinerja terlihat sebagian besar responden menyatakan cukup puas terutama pada pernyataan ke tiga, prosedur pendaftaran mudah dan tidak berbelit - belit yaitu sebanyak 120 responden dengan bobot 822 .

\section{Pelayanan Dokter}

Dari tabel 6 diatas, pada kinerja terhadap variabel pelayanan dokter. Pada kinerja terlihat sebagian besar responden menyatakan puas pada pernyataan ke sembilan, Dokter memberikan tindakan yang cepat pada saat dibutuhkan sebanyak 125 responden dengan bobot 816 .

\section{Pelayanan Perawat}

Dari tabel 6 diatas, pada kinerja terhadap variabel pelayanan perawat . pada kinerja terlihat sebagian besar responden menyatakan puas terutama pada pernyataan ke tigabelas Perawat melayani anda dengan tulus dan penuh kasih sayang, yaitu sebanyak 135 responden dengan bobot 854 .

Pelayanan Bidan

Dari tabel 6 diatas,pada kinerja terhadap variabel pelayanan bidan, pada kinerja terlihat sebagian besar menyatakan puas terutama pada pernyataan kedelapanbelas Bidan mendengarkan keluhan yang disampaikan pasien, yaitu sebanyak 133 responden dengan bobot 863 .

Pelayanan Fasilitas Medis dan Non Medis

Dari Tabel 6 diatas, pada kinerja terhadap variabel pelayanan fasilitas medis dan non medis sebagian responden besar menyatakan puas terutama pada pernyataan ke dua puluh dua, Ketersediaan obat-obatan memadai yaitu sebanyak 130 responden dengan bobot 856 .
Keadaan Lingkungan Fisik

Dari tabel 6 diatas, pada kinerja terhadap variabel keadaan lingkungan fisik sebagian besar responden menyatakan puas terutama pada pernyataan ke dua delapan Ventilasi udara cukup, yaitu sebanyak 130 responden dengan bobot 851 .

Tabel 7. Tingkatan Distribusi

\begin{tabular}{|c|c|}
\hline INTERVAL & TINGKAT KEPUASAN \\
\hline $228-410$ & Sangat Tidak Puas \\
\hline $411-593$ & Tidak Puas \\
\hline $594-776$ & Cukup Puas \\
\hline $777-959$ & Puas \\
\hline $960-1142$ & Sangat Puas \\
\hline
\end{tabular}

Sumber: Data Primer

Tabel tingkatan distribusi di atas diperoleh melalui perhitungan sebagai berikut:

Nilai Tertinggi $=$ Jumlah Responden $\mathrm{x}$ Bobot Tertinggi

$$
\begin{aligned}
& =228 \times 5 \\
& =1140
\end{aligned}
$$

Nilai Terendah $=$ Jumlah Responden $\mathrm{x}$ Bobot Terendah

$$
=228 \times 1
$$$$
=228
$$

Wilayah data $=$ Jumlah Tertinggi - Jumlah Terendah

$$
=1140-228
$$$$
=912
$$

Kelas $=$ Sangat Tidak Puas (STPs), Tidak Puas (TPs), Cukup Puas (CPs), Puas (Ps) dan Sangat Puas (SPs)

Interval $\quad=($ Wilayah Data $) /\left(\sum\right.$ Kelas $)$

$$
=912 / 5
$$$$
=182,4
$$

Tabel 8. Hasil Penghitungan Tingkat Kepuasan dari Aspek Berwujud, Keandalan, Empati, Ketanggapan dan Jaminan pada pelayaan Rawat Jalan di Puskesmas Baturetno

\begin{tabular}{|l|l|c|c|c|}
\hline \multicolumn{1}{|c|}{ Aspek } & \multicolumn{1}{|c|}{ No Pertanyaan } & Nilai & Prosentase & Keterangan \\
\hline Berwujud & P.1, P.6, P.11, P.21, P.26 & 830 & 72,76 & Puas \\
\hline Keandalan & P.2, P.7, P.12, P.22, P.27 & 822 & 72,09 & Puas \\
\hline Empati & P.3, P.8, P.13, P.23, P.28 & 831 & 72,89 & Puas \\
\hline Ketanggapan & P.4, P.9, P.14, P.24, P.29 & 831 & 72,88 & Puas \\
\hline Jaminan & P.5, P.10, P.15, P.25, P.30 & 823 & 72,22 & Puas \\
\hline
\end{tabular}

Sumber: Data primer 


\section{SIMPULAN}

1. Hasil penghitungan tingkat kepuasan pada aspek berwujud dari pelayanan rawat jalan yang meliputi loket pendaftaran, pelayanan dokter, pelayanan perawat, pelayanan fasilitas medis dan non medis dan keadaan lingkungan fisik menunjukkan rata-rata bobot 830 dengan prosentase 72,76 yang menunjukkan bahwa responden merasa puas dengan pelayanan kesehatan yang diberikan.

2. Hasil penghitungan tingkat kepuasan pada aspek keandalan pelayanan kesehatan di Puskesmas Baturetno diperoleh bobot rata rata dari variabel sebesar 822 dengan prosentase 72,09 yang menunjukkan responden merasa puas.

3. Hasil penghitungan tingkat kepuasan pada aspek empati, bobot rata-rata sebesar 831 dengan prosentase 72,89 yang menunjukkan bahwa responden merasa puas.

4. Hasil penghitungan tingkat kepuasan pada aspek ketanggapan, bobot rata-rata sebesar 831 dengan prosentase 72,88 yang menunjukkan bahwa responden merasa puas.

5. Hasil Penghitungan tingkat kepuasan pada aspek jaminan, bobot rata-rata sebesar 823 dengan prosentase 72,22 yang menunjukkan bahwa responden merasa puas.

6. Dari kelima aspek yang dinilai untuk mengetahui tingkat kepuasan pasien terhadap pelayanan kesehatan (rawat jalan) di Puskesmas Baturetno menunjukkan bahwa pasien merasa puas dengan bobot rata - rata 827 dan prosentase rata - rata sebesar 72,58.

\section{SARAN}

1. Pengendalian mutu secara terpadu dan berkesinambungan perlu dilakukan dengan mengikutsertakan seluruh karyawan sebagai tim kerja melalui gugus kendali mutu

2. Informasi alur pelayanan dan prosedur pelayanan dengan tulisan yang besar dan ditempatkan pada tempat yang mudah dibaca pengunjung Puskesmas

3. Perlu melibatkan seluruh komponen yang ada untuk mengoptimalkan pelayanan kesehatan di Puskesmas

\section{DAFTAR PUSTAKA}

Depkes RI, 2009. Profil Kesehatan Indonesia 2008. http://www.depkes.go.id.

Pohan. 2006. Jaminan Mutu Layanan kesehatan: dasar-dasar pengertian dan penerapan. Jakarta: Buku Kedokteran EGC 